\title{
DNA Damage and Cytokine Production in Non-Target Irradiated Lymphocytes
}

\author{
Jane Bryant \\ Technological University Dublin, jane.bryant@tudublin.ie \\ Laura Shields \\ University College Dublin \\ Christopher Hynes \\ Technological University Dublin
}

See next page for additional authors

Follow this and additional works at: https://arrow.tudublin.ie/radart

Part of the Medical Sciences Commons, and the Radiation Medicine Commons

\section{Recommended Citation}

Bryant J, Shields L, Hynes C, Howe O, McCleanc B, Lynga F. DNA Damage and Cytokine Production in NonTarget Irradiated Lymphocytes. Radiat Res. 2019 Jun;191(6):545-555. doi: 10.1667/RR15165.1. Epub 2019 Apr 17. PMID: 30995164.

This Article is brought to you for free and open access by the Radiation and Environmental Science Centre at ARROW@TU Dublin. It has been accepted for inclusion in Articles by an authorized administrator of ARROW@TU Dublin. For more information, please contact arrow.admin@tudublin.ie, aisling.coyne@tudublin.ie, gerard.connolly@tudublin.ie.

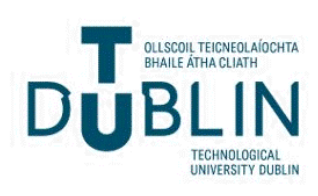




\section{Authors}

Jane Bryant, Laura Shields, Christopher Hynes, Orla L. Howe, Brendan McClean, and Fiona Lyng

This article is available at ARROW@TU Dublin: https://arrow.tudublin.ie/radart/83 


\title{
DNA Damage and Cytokine Production in Non-Target Irradiated Lymphocytes
}

\author{
Jane Bryant, ${ }^{a}$ Laura Shields, ${ }^{c, d}$ Christopher Hynes, ${ }^{a, b}$ Orla Howe, ${ }^{b}$ Brendan McClean ${ }^{c, d}$ and Fiona Lyng ${ }^{a, 1}$

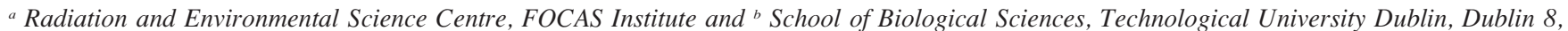 \\ Ireland; ' Medical Physics Department, St. Luke's Radiation Oncology Centre, Rathgar, Dublin, Ireland; and ' School of Physics, University College \\ Dublin, Belfield, Dublin 4, Ireland
}

Bryant, J., Shields, L., Hynes, C., Howe, O., McClean, B. and Lyng, F. DNA Damage and Cytokine Production in NonTarget Irradiated Lymphocytes. Radiat. Res. 191, 545-555 (2019).

In advanced radiotherapy, treatment of the tumor with high-intensity modulated fields is balanced with normal tissue sparing. However, the non-target dose delivered to surrounding healthy tissue within the irradiated volume is a potential cause for concern. Whether the effects observed are caused after exposure to out-of-field radiation or bystander effects through neighboring irradiated cells is not fully understood. The goal of this study was to determine the effect of exposure to out-of-field radiation in lymphocyte cell lines and primary blood cells. The role of cellular radiosensitivity in altering bystander responses in out-of-field exposed cells was also investigated. Target cells were positioned in a phantom in the center of the radiation field (in-field dose) and exposed to 2 Gy irradiation. Lymphocyte cell lines (C1, AT3ABR, Jurkat, THP-1, AT2Bi and AT3Bi) and peripheral blood were placed $1 \mathrm{~cm}$ away from the radiation field edge (out-offield dose) and received an average dose of $10.8 \pm 4.2 \mathrm{cGy}$. Double-stranded DNA damage, cell growth and gene expression were measured in the out-of-field cells. Radiosensitive AT3ABR and primary blood cells demonstrated the largest increase in $\gamma-\mathrm{H} 2 \mathrm{AX}$ foci after irradiation. Exposure of normal cells to bystander factors from irradiated radiosensitive cell lines also increased DNA damage. Expression of IL-1, IL-6, TNF $\alpha$ and TGF $\beta$ after addition of bystander factors from radiosensitive cells showed differential effects in normally responding cells, with some evidence of an adaptive response observed. Exposure to out-of-field radiation induces DNA damage and reduces growth in radiosensitive cells. Bystander factors produced by directly irradiated cells in combination with out-of-field exposure may upregulate pro- and anti-inflammatory genes in responding cells of different radiosensitivities, with the potential of affecting the tumor microenvironment. A greater understanding of the radiobiological response in normal cells outside the primary treatment field would assist in radiation treatment

\footnotetext{
1 Address for correspondence: Radiation and Environmental Science Centre, FOCAS Institute, Technological University Dublin, Kevin St, Dublin 8, Ireland; email: Fiona.lyng@dit.ie.
}

planning and in reducing early and late toxicities. () 2019 by Radiation Research Society

\section{INTRODUCTION}

Advances in radiotherapy have increased the treatment efficacy and survival rates of several prevalent cancers, however, many patients experience some level of early or late radiotherapy-related toxicity. These effects range from mild to debilitating, and can severely affect quality of life of the patient. Radiation treatments balance the delivery of a uniform dose to the tumor, resulting in DNA damage and cell death, while sparing the surrounding healthy structures. However, normal tissue within the irradiated volume affected by a low-dose bath has increasingly become a potential cause for concern [reviewed in (1)]. Radiationrelated toxicities are initiated through a combination of factors, including normal cell damage, cellular radiosensitivity and induction of an immune response (2-6). It is imperative that we continue to elucidate these factors and their relationship to the radiation dose and modality in an effort to reduce toxicities.

Normal cells can be affected in a non-targeted manner through scattered and transmitted radiation (out-of-field effects), and through cellular crosstalk, in part through soluble mediators produced by adjacent directly irradiated cells (the bystander effect). Recently, the bystander effect has been studied using clinical radiotherapy protocols to examine the effects on normal tissue during treatment. McGarry et al. used modulated fields and flask shielding during irradiation of AGO-1522b fibroblasts and DU145 prostate tumor cells to demonstrate out-of-field cell death (7). Previously published work from our group showed increased DNA damage and reduced colony volume in PNT1A normal prostate cells placed $1 \mathrm{~cm}$ away from the radiation field edge (out-of-field) (8).

The tumor microenvironment and its surrounding healthy tissue comprise a complex network of blood vessels, tumor and inflammatory cells, cytokines, chemokines and reactive 
oxygen species (ROS) (9-11). Previously published studies have documented the involvement of factors including ROS, TGF $\beta$, TNF $\alpha$ and IL- 6 in the bystander effect, induced by low- and high-dose exposure to radiation (1217). Alterations in these signaling pathways due to radiation or other treatments may affect the overall efficacy of radiation treatment. This could occur through induction of regulatory cells that inhibit anti-tumor responses, and doselimiting toxicities arising from chronic inflammation and normal cell death. These effects may be counteracted through the use of altered fractionation schedules, immunotherapy or a radioprotector such as amifostine $(1,18,19)$.

Here, we extend our previously published study on outof-field dose effects and bystander effects in a model of prostate cancer (8), to explore the responses of normal and radiosensitive lymphocyte cell lines and primary human blood cells as a surrogate for lymphocytes within the tumor microenvironment. The goal of this study was to determine if both out-of-field dose and bystander factor could affect DNA damage, growth and gene expression in lymphocyte cell lines, and elucidate these effects in the tumor microenvironment and surrounding normal tissue.

\section{MATERIALS AND METHODS}

\section{Blood Samples and Cell Lines}

Blood samples $(20 \mathrm{ml})$ were taken by venipuncture from healthy donors. Ethical approval was obtained from the Dublin Institute of Technology (DIT) Research Ethics Committee (15-32), and all donors gave informed consent. Blood was plated $2 \mathrm{~h}$ prior to irradiation, at a final volume of $5 \mathrm{ml}$ per T25 flask (Sarstedt, Numbrecht, Germany), comprising $2 \mathrm{ml}$ blood and $3 \mathrm{ml}$ RPMI 1640 medium (Sigma Aldrich, Co Wexford, Ireland) supplemented with $12.5 \%$ fetal bovine serum (FBS) and 1\% L-glutamine (Gibco, Waltham, MA). At 1 and $24 \mathrm{~h}$ postirradiation, peripheral blood mononuclear cells (PBMC) were isolated from whole blood by density centrifugation and fixed for DNA damage analysis.

In this study, Jurkat $\mathrm{T}$ cells, THP-1 monocytic cells, and $\mathrm{C} 1$, AT3ABR, AT2Bi and AT3Bi lymphoblast cell lines were used. The $\mathrm{C} 1$ (derived from a healthy donor) and AT3ABR [derived from an ataxia telangiectasia (A-T) patient] cell lines were kindly gifted by the Queensland Institute of Medical Research (Herston, Australia) (20). The AT2Bi and AT3Bi cell lines were kindly gifted from the College of Medical and Dental Sciences, University of Birmingham (Birmingham, UK). Both AT2Bi and AT3Bi are derived from A-T patients and have a total absence of the ataxia telangiectasia-mutated (ATM) protein, which is recruited to DNA double-strand breaks to initiate repair $(21,22)$. Ataxia telangiectasia is a syndrome arising from a mutation in the ATM gene, resulting in an absence of this protein (23). Among the clinical manifestations of this deficiency is sensitivity to ionizing radiation (24). Therefore, A-T cell lines were used as a surrogate for radiosensitive primary human blood cells.

\section{Culture of Cell Lines}

Jurkat T cells, THP-1 monocytic cells, and C1, AT3ABR, AT2Bi and AT3Bi lymphoblast cells were cultured in RPMI 1640 media supplemented with $12.5 \% \mathrm{FBS}$ and $1 \%$ L-glutamine, at $37^{\circ} \mathrm{C}$ and $5 \%$ $\mathrm{CO}_{2}$. Cells were seeded $18 \mathrm{~h}$ prior to irradiation, at $2 \times 10^{4}$ cells (growth curves), or $2 \times 10^{5} / \mathrm{ml}$ (all other assays), at a final volume of 5 $\mathrm{ml}$ per T25 flask (Sarstedt).

\section{Irradiation Conditions}

Cell irradiation conditions mimicked those previously reported by our group using a 6-MV photon beam produced by an Elekta Precise Linac (Elekta Oncology Systems, Crawley, UK) and a specially designed phantom permitting simultaneous irradiation of cells positioned to receive an in-field and out-of-field dose as described in detail by Shields et al. (8). Briefly, cells placed in-field (target cells) were exposed to $2 \mathrm{~Gy}$. Flasks irradiated in the out-of-field position received an average dose of $10.8 \pm 4.2 \mathrm{cGy}$, as measured using Gafchromic $^{\mathrm{TM}}$ film. Sham-irradiated flasks served as a control.

\section{Isolation of Conditioned Media}

Irradiated cell conditioned media (ICCM) was isolated from directly irradiated cells as a source of bystander factors. At $1 \mathrm{~h}$ postirradiation, sham- and in-field-exposed cells were centrifuged at $400 \mathrm{~g}$ for $5 \mathrm{~min}$. The supernatant was isolated and filtered through a $0.2-\mu \mathrm{m}$ filter (Corning ${ }^{\circledR}$ Inc., Corning, NY). Bystander factors were added to shamirradiated or out-of-field cells for $\gamma$-H2AX, growth curve or gene expression analysis $1 \mathrm{~h}$ postirradiation. The timepoint of $1 \mathrm{~h}$ was chosen in accordance with previously published studies of the bystander effect $(8,25)$.

\section{Gamma-H2AX Analysis}

DNA damage was determined using $\gamma-\mathrm{H} 2 \mathrm{AX}$ analysis and measured by flow cytometry. Cells were fixed at 1 and $24 \mathrm{~h}$ postirradiation or the addition of ICCM using $2 \%$ paraformaldehyde and stored in $70 \%$ ethanol at $-20^{\circ} \mathrm{C}$. To stain, cells were permeabilized, followed by blocking with a $4 \%$ FBS solution in phosphate buffered saline (PBS) for $30 \mathrm{~min}$. A primary antibody solution [anti-phospho-histone H2A.X (Ser139), clone JBW301, 1:500; Merck Millipore, Darmstadt, Germany] was added and incubated overnight at $4^{\circ} \mathrm{C}$, followed by $1 \mathrm{~h}$ incubation with the secondary antibody [F(ab')- goat anti-mouse $\operatorname{IgG}(\mathrm{H}+\mathrm{L})$, Alexa Fluor ${ }^{\circledR} 488,1: 200$; Thermo Fisher $^{\mathrm{TM}}$, Carlsbad, CA) at room temperature. Cells were counterstained with $1 \%$ propidium iodide solution and analyzed on an Accuri ${ }^{\mathrm{TM}} \mathrm{C} 6$ flow cytometer (BD, Oxford, UK). The mean fluorescence of 10,000 cells was calculated using the Accuri C6 Sampler software, with cells stained only with the secondary antibody serving as a negative control for each sample.

\section{Cell Growth Curves}

Growth assays were performed after irradiation or the addition of bystander factors. Cells were seeded, irradiated and counted after 5-7 days. For bystander experiments, sham-irradiated and out-of-field cells were resuspended in ICCM at $1 \mathrm{~h}$ postirradiation. Cells were counted using a Coulter ${ }^{\circledR}$ cell counter (Beckman Coulter ${ }^{\circledR}$, Maryfort, Ireland), total cell numbers calculated and analyzed with reference to shamirradiated controls.

\section{Gene Expression}

Gene expression was evaluated using real-time PCR (RT-PCR). RNA was extracted from cells using the phenol-chloroform method and concentration measured using the NanoDrop (Maestrogen, Las Vegas, NV). CDNA was synthesized using the Qscript cDNA kit (Quantabio, Beverly, MA), according to manufacturer's instructions. Primers for cytokines known to play a role in the bystander response, IL-1, IL-6, TNF $\alpha$ and TNG $\beta$, were designed (Table 1) and synthesized (Sigma-Aldrich, Wexford, Ireland) and reactions were performed in duplicate in 96-well plates (Applied Biosystems ${ }^{\circledR}$, Carlsbad, CA). Each reaction was composed of $10 \mu \mathrm{l}$ SYBR Green (Kapa Biosystems, London, UK), $1 \mu \mathrm{l}$ each of forward and reverse primers, $6 \mu \mathrm{l}$ PCR grade water and $2 \mu \mathrm{l} \mathrm{cDNA}$. Non-template controls replaced cDNA with $2<\mu l$ PCR-grade water. Reactions were run on AB 7500 fast 
TABLE 1

Forward and Reverse Primer Sequences for Housekeeping Gene Actin, and for Target Genes IL-1, IL-6, TNF $\alpha$ and TGF $\beta$

\begin{tabular}{lll}
\hline Gene & \multicolumn{1}{c}{ Forward sequence } & Reverse sequence \\
\hline Actin & 5'-ACTCTTCCAGCCTTCCTTCC & 5'-GTTGGCGTACAGGTCTTTGC \\
IL-1 & 5'-GGGCCACACATCTACTAGGC & 5'-TGGGTATCTCAGGCATCTCC \\
IL-6 & 5'-GATGCAATAACCACCCCTGACCC & 5'-CAATCTGAGGTGCCCATGCTAC \\
TNF $\alpha$ & 5'-AAGAGAATTGGGGGCTTAGG & 5'-CAGGGATCAAAGCTGTAGGC \\
TGF $\beta$ & 5'GGAGGAGGATAACACAGAGAGG & 5'-CCAAAGTGATCTTTCCAAATCC \\
\hline
\end{tabular}

PCR cycler (Applied Biosystems), with 45 cycles programmed per plate.

\section{Statistics}

Statistical analysis and graphing were performed using Prism, demo version 6 (GraphPad Software Inc., La Jolla, CA). Normal distribution of data was determined using the Kolmogorov-Smirnov and Shapiro Wilk tests. Statistical significance was calculated using paired or unpaired $t$ tests as appropriate.

\section{RESULTS}

Out-of-Field Radiation Dose Induces $\gamma$-H2AX Expression in Radiosensitive Cells

The effect of out-of-field radiation dose on DNA damage was investigated in $\mathrm{T}$ cells, monocytes, and normal and radiosensitive lymphocyte cell lines. Measurement of DNA damage by $\gamma$-H2AX staining revealed no significant change in mean fluorescence intensity (MFI) in Jurkat (at 1 and 24 h) and THP-1 cells (1 h) after irradiation (Fig. 1A and B). However, a significant increase in $\gamma-\mathrm{H} 2 \mathrm{AX}$ was observed in the radiosensitive AT3ABR cells at $1 \mathrm{~h}$ postirradiation (Fig. 1D), which was not observed in non-radiosensitive $\mathrm{C} 1$ cells (Fig. 1C). Both cell lines showed a modest increase in $\gamma$ $\mathrm{H} 2 \mathrm{AX}$ expression at $24 \mathrm{~h}$, although these changes were not significant and showed high inter-experimental variation.

\section{Out-of-Field Radiation Dose Decreases Growth of Radiosensitive Cells}

Growth curve analysis was performed to explore the effects of out-of-field dose on cell proliferation. Growth of Jurkat, THP-1 and C1 cell lines were unaffected by out-offield dose. However, there was a significant decrease in the proliferation of the radiosensitive AT3ABR cells (Fig. 2AD).

\section{Bystander Factors Isolated from Cells of Different Radiosensitivities can Alter Radiation Responses}

To model intercellular crosstalk through production of soluble mediators, ICCM was added to cells that received sham-irradiation and out-of-field dose. DNA damage and growth responses were measured in Jurkat and THP-1 cells, however, addition of ICCM did not alter these responses with ICCM alone or in combination with out-of-field placement, consistent with the findings shown in Figs. 1 and 2 (data not shown).

The potency of ICCM generated from cell lines with varying radiosensitivities was subsequently investigated. As shown in Fig. 3A, increased DNA damage was observed after treatment of sham and irradiated $\mathrm{C} 1$ cells with $\mathrm{C} 1$ ICCM, although this was not significant. The addition of radiosensitive AT3ABR sham-irradiated media and ICCM to irradiated $\mathrm{C} 1$ cells, shown in the hashed bars, resulted in a further onefold increase in $\gamma$-H2AX expression compared to cells treated with C1 ICCM. However, as shown in Fig. 3B, addition of C1 ICCM to AT3ABR cells did not alter their response.

Figure $3 \mathrm{C}$ and $\mathrm{D}$ shows the percentage cell growth after treatment compared to control levels (sham-irradiated cells treated with sham media). While $\mathrm{C} 1$ cells were unaffected by addition of $\mathrm{C} 1 \mathrm{ICCM}$, there was a relative decrease in cell growth on addition of AT3ABR ICCM, although this was not significant. A significant decrease in growth of AT3ABR cells after out-of-field dose was observed, as shown in Fig. 2D. Treatment of irradiated AT3ABR cells with sham $\mathrm{C} 1$ media also resulted in a significant increase in AT3ABR cell growth compared to addition of sham AT3ABR media. This indicates that soluble mediators from cells of different radiosensitivities can affect cell responses to radiation, regardless of whether the media was isolated from sham or irradiated cells.

\section{Out-of-Field Radiation Dose and Addition of Bystander} Factors Alters Cytokine Expression

We next investigated whether out-of-field dose and radiosensitive ICCM could modulate cytokine gene expression in responding cells. Two further radiosensitive cell lines (AT2Bi and AT3Bi) were used to determine if results with AT3ABR cells were applicable to other radiosensitive cell lines. Cytokines implicated in the bystander response, IL-1, IL-6, TNF $\alpha$ and TGF $\beta$, were measured in all cell lines.

C1 cells showed a varied pattern of expression (Fig. 4). An adaptive response was observed for IL-1; no expression was detected in out-of-field cells, while a 10-fold increase was observed in expression sham cells with ICCM. However, this difference was not significant due to interreplicate variation (Fig. 4A). No increase in expression of IL-6 was seen with either radiation or ICCM treatment (Fig. 4B). A reciprocal effect was seen with TNF $\alpha$ and TGF $\beta$, 

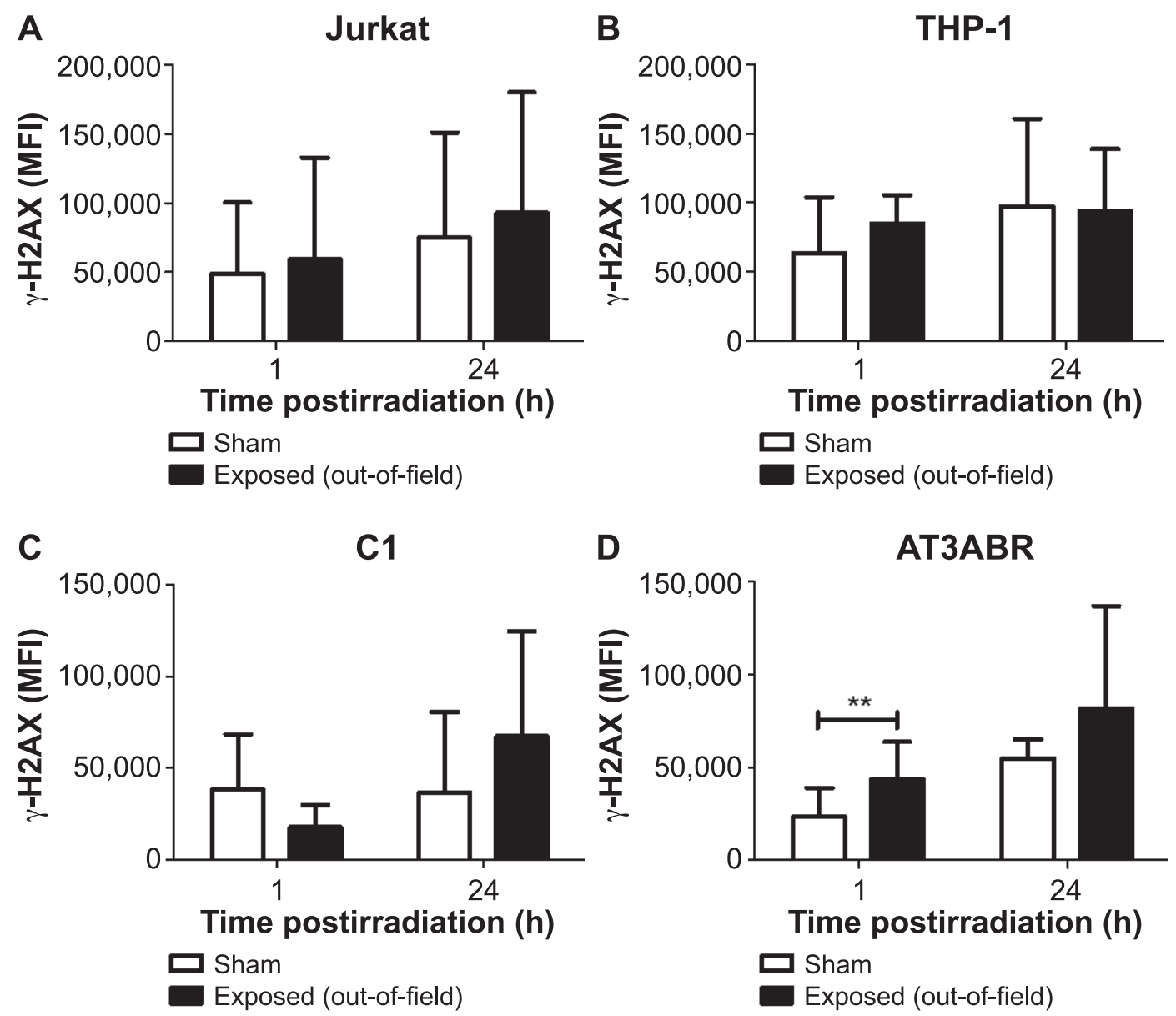

FIG. 1. Out-of-field dose increases $\gamma-\mathrm{H} 2 \mathrm{AX}$ expression in radiosensitive cells. Jurkat, THP-1, C1 and AT3ABR cells (panels A-D, respectively) were plated in T25 flasks $18 \mathrm{~h}$ prior to irradiation $\left(1 \times 10^{6}, 5 \mathrm{ml}\right)$. Cells were exposed in the out-of-field position (1 cm from target field). Nonirradiated (sham) cells served as controls. Cells were fixed $1 \mathrm{~h}$ postirradiation and stained for $\gamma-\mathrm{H} 2 \mathrm{AX}$ expression. Stained cells were analyzed using flow cytometry, with 10,000 events acquired per sample. Mean fluorescence intensity \pm SEM is shown. $\mathrm{n}$ $=5$ independent experiments. Significance was calculated using paired $t$ test, $* * P<0.01$.

where the highest TNF $\alpha$ expression was measured in out-offield cells but not with ICCM treatment, with the opposite effect observed for TGF $\beta$ expression (Fig. 4C and D).

The cytokine expression of the radiosensitive cell lines (AT3ABR, AT2Bi and AT3Bi) differed from the C1 cell line, but also from each other. The response of AT3ABR was similar to that of $\mathrm{C} 1$ in IL- 1 and IL- 6 expression, but showed no TNF $\alpha$ expression after an out-of-field dose alone. An adaptive effect was observed in the AT3ABR cells for TGF $\beta$ expression, with a 680 -fold increase in the sham AT3ABR cells treated with ICCM, which was reduced to a 200-fold increase when the cells received an out-of-field dose and ICCM. However, this did not reach statistical significance due to high variation. Similar patterns in IL-6 expression were observed in both A-T cell lines, with no expression in out-of-field cells, a modest increase in sham cells with ICCM, which was further increased when out-of-field cells and ICCM were combined. No expression of TNF $\alpha$ was observed in either A-T cell lines. Expression of TGF $\beta$ in AT2Bi cells mirrored that of AT3ABR cells, however, the only increase observed in AT3Bi cells was in the cells positioned out-of-field and treated with ICCM (175-fold compared to sham) (Figs. 4A-5D).

\section{Treatment of Normal Responding Cells with ICCM from Cells of Different Radiosensitivities Varies Their Cytokine Gene Expression Pattern}

As shown in Fig. 3, treatment with radiosensitive AT3ABR ICCM increased DNA damage and reduced the growth of $\mathrm{C} 1$ cells. To determine if this effect was also observed in cytokine gene expression patterns, $\mathrm{C} 1$ cells were treated with radiosensitive ICCM from all three A-T cell lines (Fig. 5).

The expression pattern of IL-1 was not altered by the addition of radiosensitive ICCM, with an adaptive effect observed, as shown in Fig. 4. However, there was an increase in IL-6 expression in sham cells treated with radiosensitive ICCM, the most marked observed with AT3ABR ICCM with a threefold increase over cells treated with $\mathrm{C} 1 \mathrm{ICCM}$ (Fig. 5A). There were no changes in IL-6 

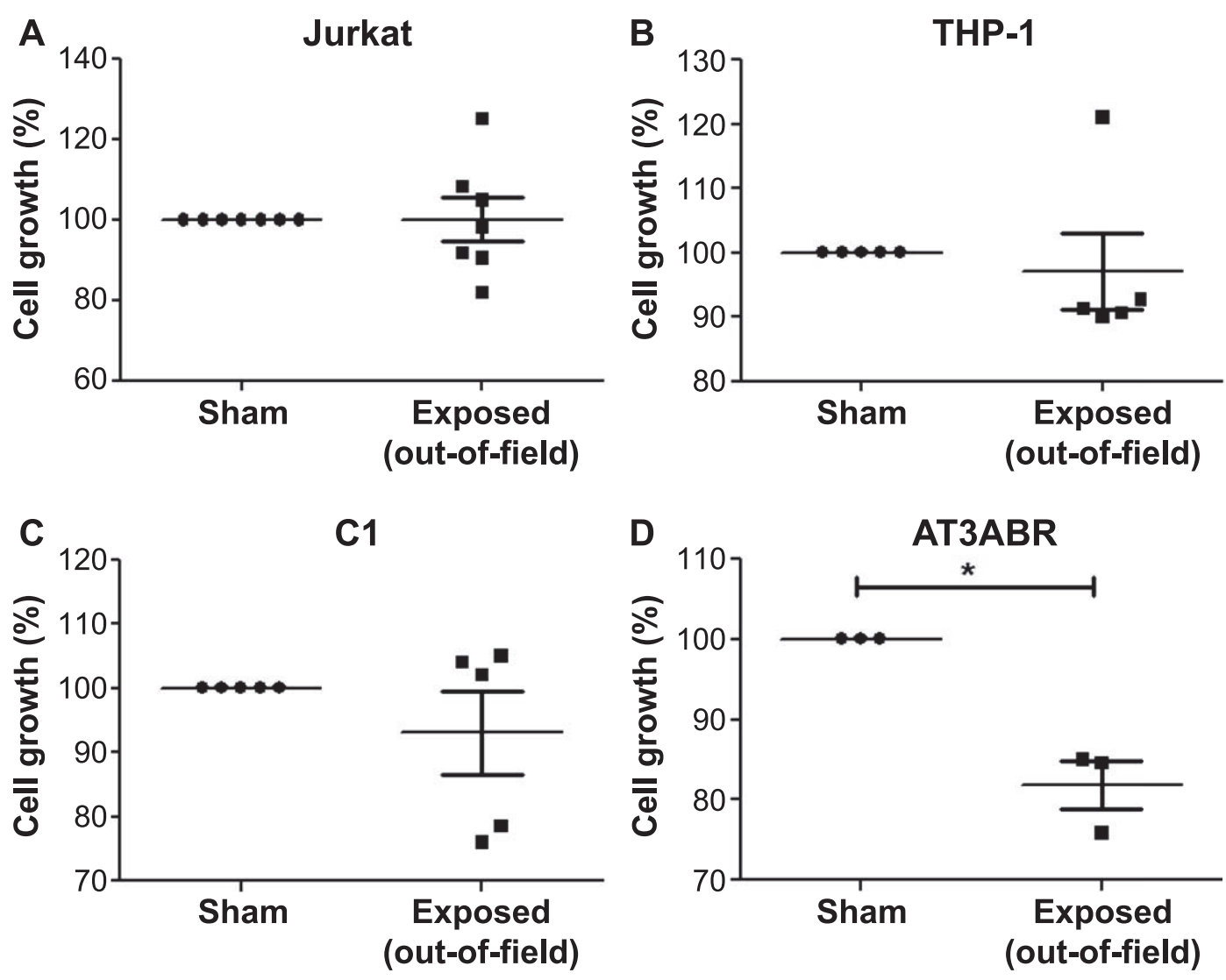

FIG. 2. Out-of-field dose decreases growth of radiosensitive cells. Jurkat, THP-1, C1 and AT3ABR cells (panels A-D, respectively) were plated in T25 flasks $18 \mathrm{~h}$ prior to irradiation $\left(5 \times 10^{4}, 5 \mathrm{ml}\right)$. Cells were exposed in the out-of-field position (1 cm from target field). Nonirradiated (sham) cells served as controls. Cells were counted at day 5 postirradiation using a cell counter and the irradiated flasks were expressed as a percentage of the sham flasks. Pooled data from 3-5 independent experiments are shown, mean \pm SEM, and significance calculated using paired $t$ test on raw data, $* P<0.05$.

expression, except for a large increase in expression after addition of AT3Bi ICCM to irradiated C1 cells (Fig. 5B). There was no increase in TNF $\alpha$ expression above that seen with out-of-field dose alone (Fig. 5C). Addition of AT2Bi and AT3Bi ICCM increased TGF $\beta$ expression in $\mathrm{C} 1$ cells, although this occurred whether the cells had been irradiated or not. This effect was also found in $\mathrm{C} 1$ cells treated with C1 ICCM, where an increase in TGF $\beta$ expression was observed after treatment with ICCM regardless of exposure (Fig. 5D).

A correlation analysis was performed to determine if there was a relationship between $\gamma$-H2AX expression and cytokine expression in $\mathrm{C} 1$ cells. All treatment parameters were included. Figure 6 show an inverse correlation between normalized $\gamma-\mathrm{H} 2 \mathrm{AX}$ expression and TNF $\alpha$ expression; where one mediator increased, the other decreased.

\section{Out-of-Field Radiation Dose Increases DNA Damage in Primary Human Peripheral Blood Mononuclear Cells}

We next sought to determine if out-of-field dose induced DNA damage in primary human blood cells. As shown in Fig. 7, there was a significant increase in $\gamma$-H2AX expression after out-of-field dose at $1 \mathrm{~h}$, which had decreased to baseline levels after $24 \mathrm{~h}$. These data indicate that the out-of-field dose can induce the DNA damage response in primary human blood cells.

\section{DISCUSSION}

As radiotherapy techniques advance, continued exploration of normal tissue effects is important to reduce radiationinduced early and late toxicities. In the current work, we used a clinically relevant experimental setup, whereby the target cells are exposed to $2 \mathrm{~Gy}$, and the out-of-field cells are positioned $1 \mathrm{~cm}$ from the target to model normal tissue effects. Using this model, we have previously shown that out-of-field dose induced DNA damage in normal prostate cells (8). Here, we extended these findings to normal and radiosensitive lymphocyte cell lines as a surrogate for tumor-adjacent immune cells. Furthermore, we treated outof-field cells with ICCM to examine the effects of bystander factors produced by irradiated tumor cells during radiation treatment.

The most significant effect of out-of-field dose was observed in radiosensitive cells, with an increase in $\gamma$ - 

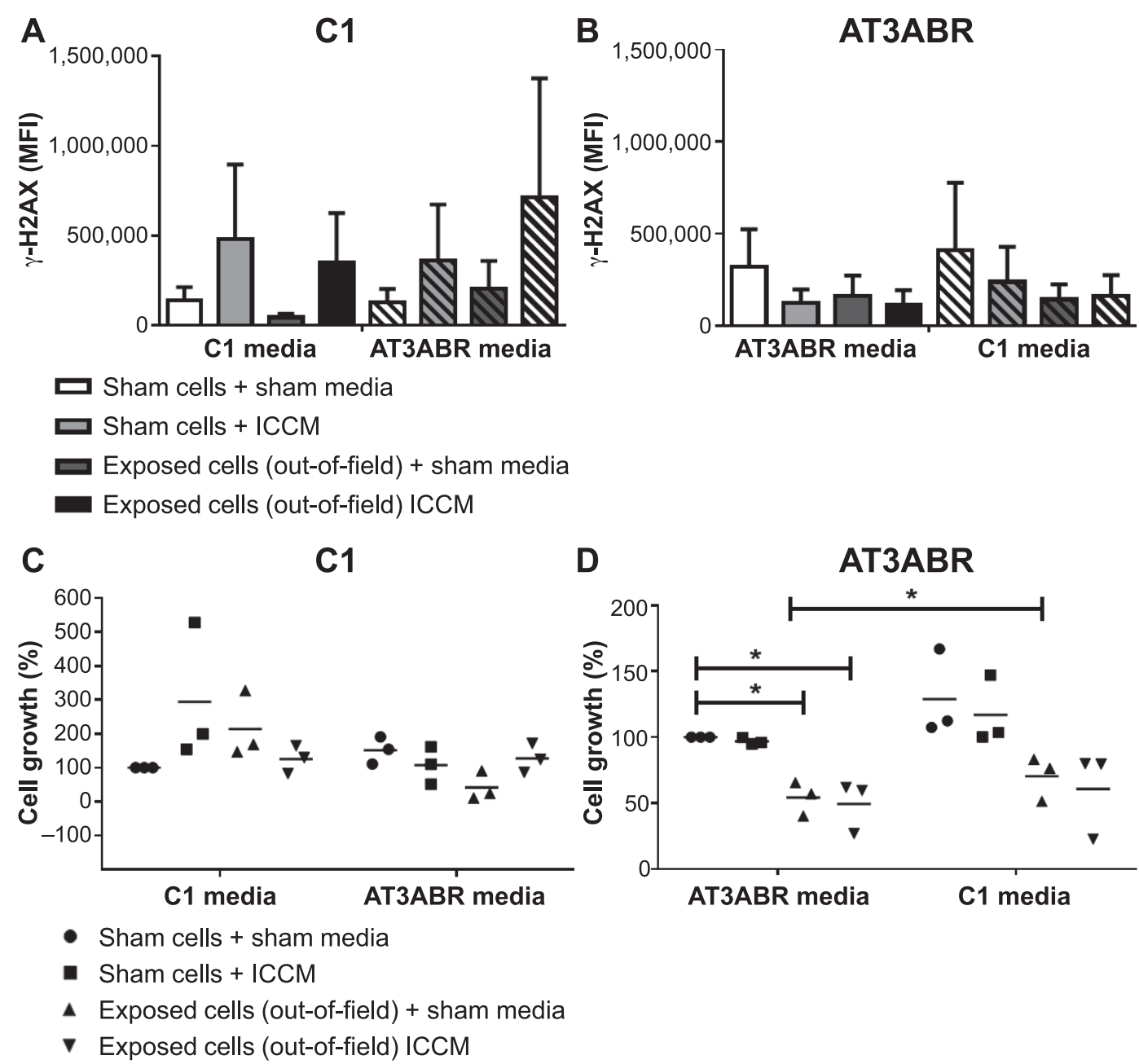

FIG. 3. Radiosensitive ICCM alters normal cell responses to out-of-field dose and autologous ICCM. C1 and AT3ABR cells were plated for $\gamma-\mathrm{H} 2 \mathrm{AX}$ and growth assays as before, with ICCM generated as described in Fig. 3. ICCM from each cell line was added to their own cell line (open bars) and to the opposite cell line (hashed bars), both sham-irradiated and out-of-field dose. After $1 \mathrm{~h}$, cells were isolated for $\gamma-\mathrm{H} 2 \mathrm{AX}$ (panels A and B) and growth assays (panels $\mathrm{C}$ and $\mathrm{D}$ ). Data from three independent experiments are shown, mean \pm SEM with significance calculated using paired $t$ tests, ${ }^{*} P<0.05$.

$\mathrm{H} 2 \mathrm{AX}$ at $1 \mathrm{~h}$ postirradiation, and a decrease in cell growth at day 5 postirradiation (Figs. 1D and 2D). Although the dose received by out-of-field cells is in the hyperradiosensitivity range (maximum dose of $0.2 \mathrm{~Gy}$ ), no other cell line tested showed a significant increase in DNA damage or decrease in growth. This agrees with Park et al. who showed that direct irradiation with doses of 0.05 and 0.1 Gy had no significant effect on the viability of THP-1 or Jurkat cells (26).

A significant increase in expression of $\gamma-\mathrm{H} 2 \mathrm{AX}$ in healthy control PBMC was also seen after the out-of-field dose (Fig. 7). We observed that the early increase in $\gamma$-H2AX was reduced to baseline after $24 \mathrm{~h}$; however, it is unknown whether this was due to DNA repair or apoptosis. These findings agree with a previously published study by Siva $e t$ al., who measured $\gamma-\mathrm{H} 2 \mathrm{AX}$ foci in PBMC of non-small lung cancer patients before, during and after fractionated radiation therapy (27). They observed increased $\gamma$-H2AX foci at $1 \mathrm{~h}$ postirradiation, which returned to baseline levels at $24 \mathrm{~h}$. The PBMC represented the normal cells in the target volume in these patients; however, they also measured DNA damage in eyebrow hair follicles as a model for out-of-field tissues and the abscopal effect, which is the clinical manifestation of the bystander effect. They demonstrated a significant increase in $\gamma$-H2AX foci up to 4 weeks postirradiation, showing evidence of sustained DNA damage initiated through circulating cytokines and chemokines (27).

When normally responding $\mathrm{C} 1$ cells were treated with ICCM from radiosensitive cells, an increase in DNA damage in cells that received an out-of-field dose was observed (Fig. 3A). We also saw a modest decrease in cell proliferation, but this was limited to sham cells treated with ICCM. This could indicate an adaptive response to the priming dose of radiation, which is specific to ICCM derived from AT3ABR cells, given that this also occurred 

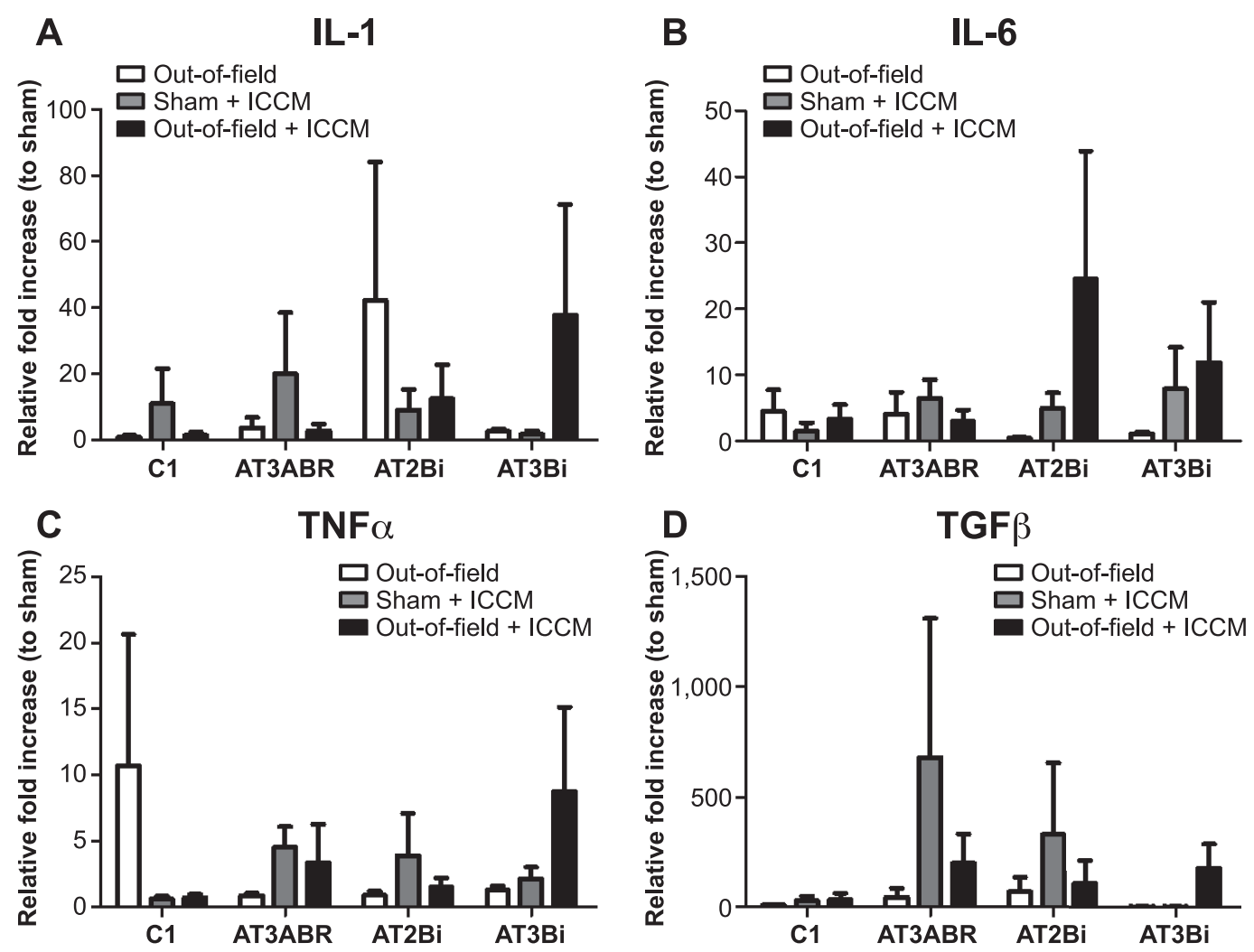

FIG. 4. Normal and radiosensitive cells show different patterns of cytokine gene expression after out-of-field dose and ICCM. C1, AT3ABR, AT2Bi and AT3Bi cells were plated for out-of-field dose and ICCM generation $18 \mathrm{~h}$ prior to irradiation $\left(1 \times 10^{6}, 5 \mathrm{ml} / \mathrm{T} 25\right.$ flask). At $1 \mathrm{~h}$ postirradiation or addition of ICCM, cells were resuspended in TRI Reagent for RNA extraction. Panels A-D: Expression of IL-1, IL-6, TNF $\alpha$ and TGF $\beta$, respectively, was measured by RT-PCR (SYBR Green, ABI 7500 cycler) and fold changes calculated with respect to sham values. Data from 4-5 independent experiments are shown, mean $\pm \mathrm{SEM}$.

with irradiated AT3ABR cells and AT3ABR ICCM (Fig. 3D). It is unclear whether this effect of radiosensitive cell ICCM is due to a factor that is not present in normal cell ICCM, or a change in concentration of a factor present in both normal and radiosensitive ICCM. It was previously shown that the bystander factors generated from cells that were deficient in DNA repair mechanisms were more toxic (28-30). Nagasawa et al. found that when wild-type $\mathrm{CHO}$ cells were treated with alpha particles, for every nucleus that was traversed, 3-4 nearby cells were at risk of mutations. However, up to 50 nearby cells were at risk of mutation after a single nuclei traversal in DNA repair-deficient cells. Furthermore, analysis of the nature of these mutations revealed that approximately $80 \%$ of the mutations in the DNA repair-deficient cells were deletions, compared to $50 \%$ in the wild-type cells (28). Mothersill et al. demonstrated that repair-deficient cells produced more cell death in both autologous and reporter cell lines than repair-proficient cells, and postulated that repair-deficient cells induce increased death as a response to increased levels of DNA damage (30). An effect was also seen in C1 and AT3ABR responder cells on addition of ICCM from sham-irradiated cells (Fig. 3). Sham ICCM from AT3ABR cells increased DNA damage in irradiated $\mathrm{C} 1$ cells, while sham C1 ICCM increased the proliferation of irradiated AT3ABR cells. The reasons for this are unclear; however, it has previously been shown that ATM-deficient cells have a higher level of basal DNA damage and chromosomal instability, which requires more time to resolve compared to normally responding cells $(31,32)$. It is possible that sham-irradiated AT3ABR cells underwent some basal damage, which took longer to resolve and thus, there was some level of mediators still present in the ICCM after the 1-h timepoint of isolation. Sham C1 ICCM may have contained some mediators that mitigated the decrease in proliferation of the irradiated AT3ABR cells, however, further investigation is necessary to determine what these factors are. It was shown by Furlong et al. that apoptotic pathways differ between those induced by direct irradiation, and through the bystander effect. The majority of apoptosis-related genes were expressed at $24 \mathrm{~h}$ after ICCM transfer (33). These data may explain our observations in the AT3ABR cell line, and the differential effects seen at $1 \mathrm{~h}$ (DNA damage) and day 5 (cell proliferation). However, further studies are needed to establish which cell death pathways are induced in our model.

Further insight into this model may be reflected in the differences in genes critical for the DNA damage response. The radiosensitive cell models used in this study were 

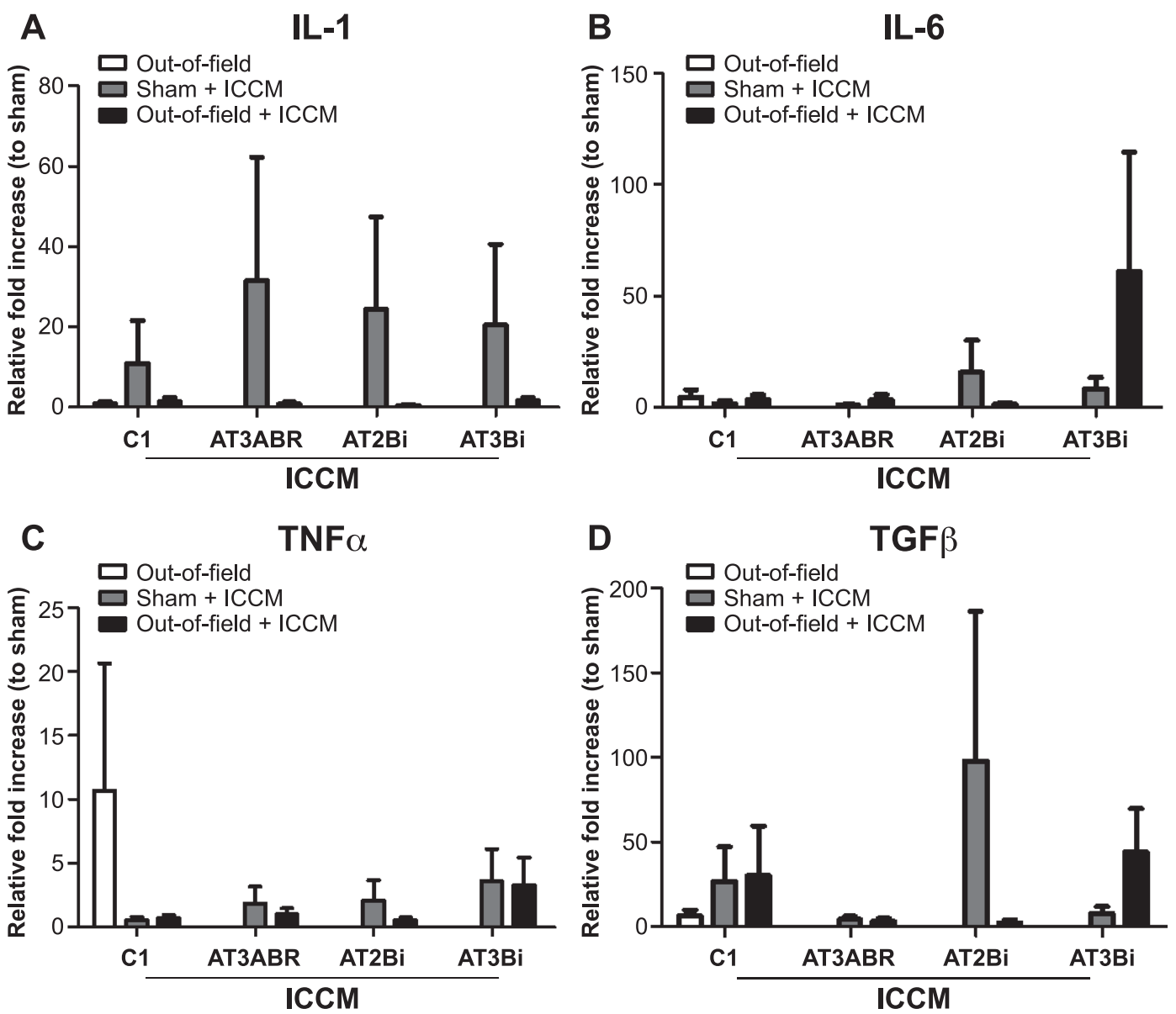

FIG. 5. Radiosensitive ICCM alters cytokine gene expression of normal cells. C1 cells were plated for out-offield dose, with $\mathrm{C} 1$, AT3ABR, AT2Bi and AT3Bi cells plated for ICCM generation as described here. ICCM from all cell lines was added to sham-irradiated and out-of-field $\mathrm{C} 1$ cells at $1 \mathrm{~h}$ postirradiation. After incubation for $1 \mathrm{~h}$, cells were isolated for RNA extraction and analysis as previously described. Panels A-D: Shown are fold changes in expression of IL-1, IL-6, TNF $\alpha$ and TGF $\beta$, respectively, with respect to sham C1 cells. Data are representative of 4-5 independent experiments, mean \pm SEM.

isolated from A-T patients and thus, are defective or deficient in ATM. The DNA damage response is initiated by members of the phosphatidylinositol 3-kinase-related kinase (PIKK) family, including ATM, ataxia telangiectasia-mutated and Rad3-related (ATR), and DNA-dependent protein kinase catalytic subunit (DNA-PKcs). Research over the past decade has shown that these DNA damage sensors play different roles in directly irradiated cells and cells damaged through the bystander response (34-36). While ATM and ATR are both employed in the DNA damage response in directly irradiated cells, ATR predominates in bystander cells, with ATM activated downstream and dependent on ATR $(34,35)$. Studies using ATM-deficient cell lines showed that while $\gamma-\mathrm{H} 2 \mathrm{AX}$ was significantly increased in bystander cells, there was no decrease in their survival, although this was observed if the cells were directly irradiated (34). It was also shown that ATR could substitute for ATM in ATM-deficient cells in repairing endogenous damage, but not that induced by ionizing radiation (37). Data in this study showed increased DNA damage and decreased survival in ATM-deficient out-of- field cells, and an ability of these cells to produce bystander responses in normally responding cells without showing a bystander response themselves (Figs. 1-3). However, ICCM from all three ATM-deficient cell lines could differentially modulate cytokine gene expression in an autologous manner and in normally responding cells (Figs. 4 and 5). As briefly discussed in the Materials and Methods, AT3ABR, AT2Bi and AT3Bi do not have functional ATM; however, their expression of ATR and other related proteins is expected to be complete. Further investigation is required to determine what DNA damage response pathways are involved in the response to out-of-field dose and production or response to bystander factors.

The tumor microenvironment and its surrounding healthy tissue consist of an interplay between the tumor cells and their associated immune, endothelial and stromal cells, blood vessels, mediators of oxidative stress, chemokines and cytokines. Because of this heterogeneity, some cells may be more radiosensitive than others, due to their phenotype or their position within the cell cycle. Furthermore, early and late radiotherapy-related toxicities, such as 

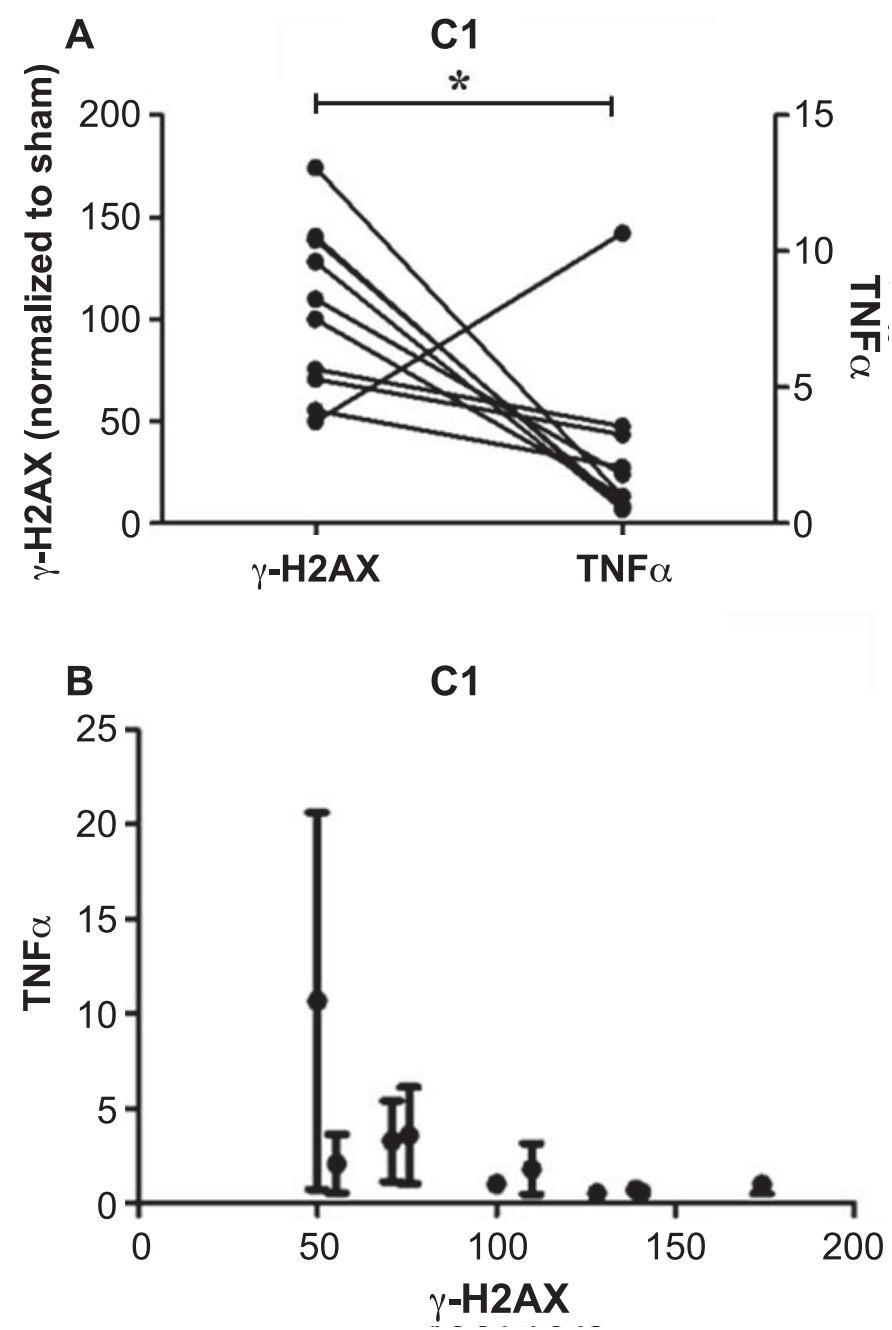

FIG. 6. Inverse correlation observed between $\mathrm{TNF} \alpha$ and $\gamma$-H2AX expression in normal responding cells. $\mathrm{C} 1$ cells were plated for the out-of-field dose as before and ICCM from all cell lines was added to sham-irradiated and out-of-field $\mathrm{C} 1$ cells at $1 \mathrm{~h}$ postirradiation. After incubation for $1 \mathrm{~h}$, cells were isolated for RNA extraction and analysis. Shown is a correlation analysis of TNF $\alpha$ and $\gamma-\mathrm{H} 2 \mathrm{AX}$ MFI of all $\mathrm{C} 1$ cells, treated with ICCM or untreated. $* P=0.0341, \mathrm{R}^{2}=$ 0.4488 , Pearson $=-0.6699$.

late radiation-induced fibrosis, have a strong immune component. This is initiated with an early release of cytokines such as TNF $\alpha$, IL- 1 and IL- 6 , followed by TGF $\beta$ [reviewed in (5)]. We therefore investigated cytokine gene expression in normally responding cells and whether this response was altered by radiosensitive ICCM. We observed a highly variable gene expression pattern in both normal and radiosensitive cell lines, and in normal cells after ICCM treatment. Both pro- and anti-inflammatory genes were expressed after out-of-field dose, and both were increased by treatment with radiosensitive ICCM, although this was not observed in every cell-ICCM combination across all cytokines measured.

It is known that low doses of radiation $(<1 \mathrm{~Gy})$ stimulate an anti-inflammatory milieu (38). This results in an increase in TGF $\beta$ production and a decrease in IL- $1 \beta$ and TNF $\alpha$

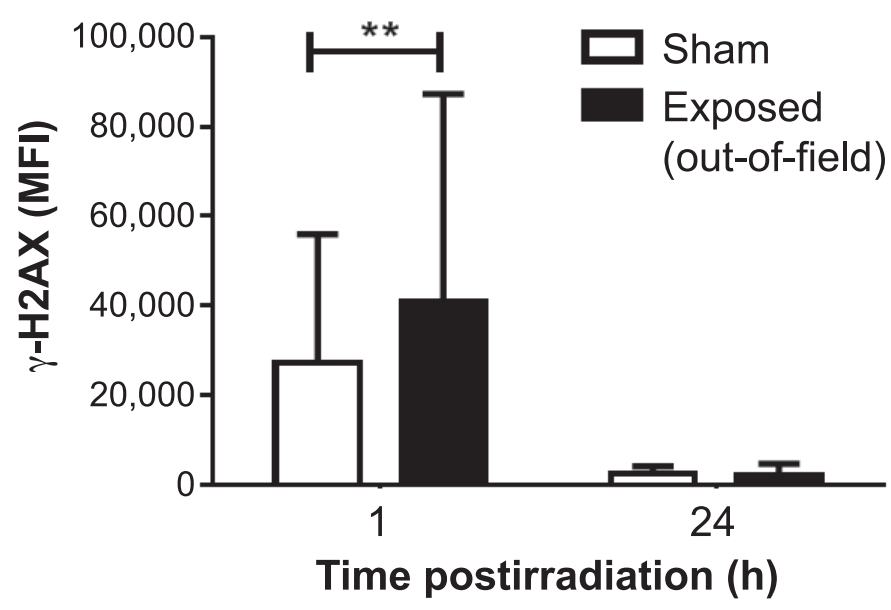

FIG. 7. Out-of-field dose induces DNA damage in primary human blood mononuclear cells. Whole blood was obtained by venipuncture and plated in T25 flasks on the day of irradiation $(2 \mathrm{ml} \mathrm{blood,} 3 \mathrm{ml}-$ RPMI/flask). Flasks received an out-of-field dose, with target field exposed to 2 Gy. Nonirradiated flasks served as sham cells. At 1 and $24 \mathrm{~h}$ postirradiation, PBMC were isolated by density centrifugation and fixed for $\gamma-\mathrm{H} 2 \mathrm{AX}$ analysis. Shown are data from six donors, mean MFI \pm SEM. Significance was calculated using Wilcoxon rank test, $* * P<0.01$

(39). This anti-inflammatory environment favors the M2 phenotype of macrophages within the tumor and surrounding area, which further perpetuates this suppressive and protumor environment (40). We observed an increase in IL-1 gene expression in radiosensitive cells compared to normal cells, and a large increase in normal cells that had been treated with radiosensitive ICCM. However, these levels were reduced to baseline on combining out-of-field dose and ICCM, indicating that low-dose exposure has an antiinflammatory effect. A similar effect was previously shown using a murine model of prostate cancer, where peritoneal macrophages from radiosensitive mice produced decreased amounts of IL- $1 \beta$ after 0.5 and $0.7 \mathrm{~Gy}$ irradiation (41). We also observed low expression of TNF $\alpha$ in all radiosensitive cells and cells treated with radiosensitive ICCM. In fact, TNF $\alpha$ was the only gene to significantly correlate with $\gamma$ $\mathrm{H} 2 \mathrm{AX}$ levels in these cells, showing an inverse relationship: the lower the expression of TNF $\alpha$, the higher the $\gamma-\mathrm{H} 2 \mathrm{AX}$ expression (Fig. 6). It is known that at higher concentrations, TNF $\alpha$ has anti-tumor effects, although at lower concentrations, it is pro-tumor and promotes cell survival (42). We observed an increased expression of TGF $\beta$ in both radiosensitive cells and in normal cells treated with radiosensitive ICCM. Wunderlich et al. recently reported that $0.1,0.3$ and 0.5 Gy X-ray irradiation to the peritoneal macrophages from radiosensitive $(\mathrm{Balb} / \mathrm{c})$ mice resulted in a significant increase in TGF $\beta$ and reduced IL- $1 \beta$, indicating an immunosuppressive environment after low-dose irradiation (43). The data presented here show a wide-ranging response to both bystander factors from cells of varying radiosensitivities and out-of-field doses. Although further work is required to determine if these responses are also 
observed at the protein level, it could be hypothesized that radiosensitive individuals may favor a more immunosuppressive tumor microenvironment, which could affect antitumor responses.

\section{CONCLUSION}

This study shows that out-of-field dose induces early DNA damage in radiosensitive cell lines and primary blood cells and reduces cell proliferation over five days. This has implications for damage of normal cells during radiation therapy, particularly in radiosensitive individuals. Additionally, bystander factors produced by directly irradiated cells may upregulate cytokine gene expression in a pro- or antiinflammatory manner, which may affect neighboring nonirradiated cells. These responses could be further altered by the combination of conditioned media and out-of-field dose, potentially skewing the response towards a more immunosuppressive and pro-tumor milieu. Given these and other findings, the mechanism of the complicated interplay of these factors within the tumor microenvironment warrants further study, with a view toward increasing the efficacy of radiation therapy and decreasing early and late toxicities for all patients.

\section{ACKNOWLEDGMENT}

We thank Professor Malcolm Taylor of the Institute of Cancer and Genomic Sciences at the University of Birmingham, UK, for kindly providing us with the AT2Bi and AT3Bi cell lines.

Received: June 19, 2018; accepted: March 12, 2019; published online: April 17, 2019

\section{REFERENCES}

1. Deloch L, Derer A, Hartmann J, Frey B, Fietkau R, Gaipl US. modern radiotherapy concepts and the impact of radiation on immune activation. Front Oncol 2016; 6:141.

2. Chen Y, Williams J, Ding I, Hernady E, Liu W, Smudzin T, et al. Radiation pneumonitis and early circulatory cytokine markers. Semin Radiat Oncol 2002; 12:26-33.

3. Rubin P, Johnston CJ, Williams JP, McDonald S, Finkelstein JN. A perpetual cascade of cytokines postirradiation leads to pulmonary fibrosis. Int J Radiat Oncol Biol Phys 1995; 33:99-109.

4. Williams J, Chen Y, Rubin P, Finkelstein J, Okunieff P. The biological basis of a comprehensive grading system for the adverse effects of cancer treatment. Semin Radiat Oncol 2003; 13:182-8.

5. Bentzen SM. Preventing or reducing late side effects of radiation therapy: radiobiology meets molecular pathology. Nat Rev Cancer 2006; 6:702-13.

6. Beaton LA, Ferrarotto C, Marro L, Samiee S, Malone S, Grimes S, et al. Chromosome damage and cell proliferation rates in in vitro irradiated whole blood as markers of late radiation toxicity after radiation therapy to the prostate. Int $\mathrm{J}$ Radiat Oncol Biol Phys 2013; 85:1346-52.

7. McGarry CK, Butterworth KT, Trainor C, McMahon SJ, O'Sullivan JM, Prise KM, et al. In-vitro investigation of out-offield cell survival following the delivery of conformal, intensitymodulated radiation therapy (IMRT) and volumetric modulated arc therapy (VMAT) plans. Phys Med Biol 2012; 57:6635-45.

8. Shields L, Vega-Carrascal I, Singleton S, Lyng FM, McClean B.
Cell survival and DNA damage in normal prostate cells irradiated out-of-field. Radiat Res 2014; 182:499-506.

9. Cook JA, Gius D, Wink DA, Krishna MC, Russo A, Mitchell JB. Oxidative stress, redox, and the tumor microenvironment. Semin Radiat Oncol 2004; 14:259-66.

10. Grabbe S, Bruvers S, Granstein RD. Effects of immunomodulatory cytokines on the presentation of tumor-associated antigens by epidermal Langerhans cells. J Invest Dermatol 1992; 99:66S-8S.

11. Merlo A, Juretic A, Zuber M, Filgueira L, Luscher U, Caetano V, et al. Cytokine gene expression in primary brain tumours, metastases and meningiomas suggests specific transcription patterns. Eur J Cancer 1993; 29A:2118-25.

12. Shao C, Lyng FM, Folkard M, Prise KM. Calcium fluxes modulate the radiation-induced bystander responses in targeted glioma and fibroblast cells. Radiat Res 2006; 166:479-87.

13. Iyer R, Lehnert BE. Low dose, low-LET ionizing radiationinduced radioadaptation and associated early responses in unirradiated cells. Mutat Res 2002; 503:1-9.

14. Shao C, Folkard M, Prise KM. Role of TGF-beta1 and nitric oxide in the bystander response of irradiated glioma cells. Oncogene 2008; 27:434-40.

15. Shareef MM, Cui N, Burikhanov R, Gupta S, Satishkumar S, Shajahan S, et al. Role of tumor necrosis factor-alpha and TRAIL in high-dose radiation-induced bystander signaling in lung adenocarcinoma. Cancer Res 2007; 67:11811-20.

16. Desai S, Kumar A, Laskar S, Pandey BN. Cytokine profile of conditioned medium from human tumor cell lines after acute and fractionated doses of gamma radiation and its effect on survival of bystander tumor cells. Cytokine 2013; 61:54-62.

17. Dong $\mathrm{C}, \mathrm{He} \mathrm{M}, \mathrm{Tu} \mathrm{W}$, Konishi T, Liu W, Xie Y, et al. The differential role of human macrophage in triggering secondary bystander effects after either gamma-ray or carbon beam irradiation. Cancer Lett 2015; 363:92-100.

18. Kouvaris JR, Kouloulias VE, Vlahos LJ. Amifostine: the first selective-target and broad-spectrum radioprotector. Oncologist 2007; 12:738-47.

19. Kao J, Ko EC, Eisenstein S, Sikora AG, Fu S, Chen SH. Targeting immune suppressing myeloid-derived suppressor cells in oncology. Crit Rev Oncol Hematol 2011; 77:12-9.

20. Zhang N, Chen P, Khanna KK, Scott S, Gatei M, Kozlov S, et al. Isolation of full-length ATM cDNA and correction of the ataxiatelangiectasia cellular phenotype. Proc Natl Acad Sci U S A 1997; 94:8021-6.

21. Taylor AM, Flude E, Laher B, Stacey M, McKay E, Watt J, et al. Variant forms of ataxia telangiectasia. J Med Genet 1987; 24:66977.

22. Lee JH, Paull TT. Direct activation of the ATM protein kinase by the Mre11/Rad50/Nbs1 complex. Science 2004; 304:93-6.

23. Savitsky K, Bar-Shira A, Gilad S, Rotman G, Ziv Y, Vanagaite L, et al. A single ataxia telangiectasia gene with a product similar to PI-3 kinase. Science 1995; 268:1749-53.

24. Cunlift PN, Mann JR, Cameron AH, Roberts KD, Ward HN, Radiosensitivity in ataxia-telangiectasia. $\mathrm{Br} \mathrm{J}$ Radiol 1975; 48:374-6.

25. Lyng FM, Howe OL, McClean B. Reactive oxygen speciesinduced release of signalling factors in irradiated cells triggers membrane signalling and calcium influx in bystander cells. Int $\mathrm{J}$ Radiat Biol 2011; 87:683-95.

26. Park HS, You GE, Yang KH, Kim JY, An S, Song JY, et al. Role of AKT and ERK pathways in controlling sensitivity to ionizing radiation and adaptive response induced by low-dose radiation in human immune cells. Eur J Cell Biol 2015; 94:653-60.

27. Siva S, Lobachevsky P, MacManus MP, Kron T, Moller A, Lobb $\mathrm{RJ}$, et al. Radiotherapy for non-small cell lung cancer induces DNA damage response in both irradiated and out-of-field normal tissues. Clin Cancer Res 2016; 22:4817-26.

28. Nagasawa H, Huo L, Little JB. Increased bystander mutagenic 
effect in DNA double-strand break repair-deficient mammalian cells. Int J Radiat Biol 2003; 79:35-41.

29. Mothersill C, Seymour CB. Bystander and delayed effects after fractionated radiation exposure. Radiat Res 2002; 158:626-33.

30. Mothersill C, Seymour RJ, Seymour CB. Bystander effects in repair-deficient cell lines. Radiat Res 2004; 161:256-63.

31. Moreno Galarraga L, Santos Perez JL, Ramirez-Tortosa MC, Quiles Morales JL, Granados Principal S, Martinez de Victoria Munoz E, et al. Use of the comet test to assess DNA damage in children with ataxia-telangiectasia and their relatives. J Investig Allergol Clin Immunol 2008; 18:137-8.

32. Palazzo RP, Jardim LB, Bacellar A, de Oliveira FR, Maraslis FT, Pereira CHJ, et al. DNA damage and repair in individuals with ataxia-telangiectasia and their parents. Mutat Res 2018; 836:1226.

33. Furlong H, Mothersill C, Lyng FM, Howe O. Apoptosis is signalled early by low doses of ionising radiation in a radiationinduced bystander effect. Mutat Res 2013; 741-42:35-43.

34. Burdak-Rothkamm S, Rothkamm K, Prise KM. ATM acts downstream of ATR in the DNA damage response signaling of bystander cells. Cancer Res 2008; 68:7059-65.

35. Burdak-Rothkamm S, Short SC, Folkard M, Rothkamm K, Prise KM. ATR-dependent radiation-induced gamma $\mathrm{H} 2 \mathrm{AX}$ foci in bystander primary human astrocytes and glioma cells. Oncogene 2007; 26:993-1002.

36. Burdak-Rothkamm S, Rothkamm K, McClelland K, Al Rashid ST, Prise KM. BRCA1, FANCD2 and Chk1 are potential molecular targets for the modulation of a radiation-induced DNA damage response in bystander cells. Cancer Lett 2015; 356:454-61.
37. Marcelain K, De La Torre C, Gonzalez P, Pincheira J. Roles of nibrin and AtM/ATR kinases on the G2 checkpoint under endogenous or radio-induced DNA damage. Biol Res 2005; $38: 179-85$.

38. Rodel F, Frey B, Gaipl U, Keilholz L, Fournier C, Manda K, et al. Modulation of inflammatory immune reactions by low-dose ionizing radiation: molecular mechanisms and clinical application. Curr Med Chem 2012; 19:1741-50.

39. Rodel F, Frey B, Multhoff G, Gaipl U. Contribution of the immune system to bystander and non-targeted effects of ionizing radiation. Cancer Lett 2015; 356:105-13.

40. Lumniczky K, Safrany G. The impact of radiation therapy on the antitumor immunity: local effects and systemic consequences. Cancer Lett 2015; 356:114-25.

41. Frischholz B, Wunderlich R, Ruhle PF, Schorn C, Rodel F, Keilholz L, et al. Reduced secretion of the inflammatory cytokine IL-1beta by stimulated peritoneal macrophages of radiosensitive Balb/c mice after exposure to 0.5 or 0.7 Gy of ionizing radiation. Autoimmunity 2013; 46:323-8.

42. Kim S, Takahashi H, Lin WW, Descargues P, Grivennikov S, Kim $\mathrm{Y}$, et al. Carcinoma-produced factors activate myeloid cells through TLR2 to stimulate metastasis. Nature 2009; 457:102-6.

43. Wunderlich R, Ernst A, Rodel F, Fietkau R, Ott O, Lauber K, et al. Low and moderate doses of ionizing radiation up to 2 Gy modulate transmigration and chemotaxis of activated macrophages, provoke an anti-inflammatory cytokine milieu, but do not impact upon viability and phagocytic function. Clin Exp Immunol 2015; 179:50-61. 